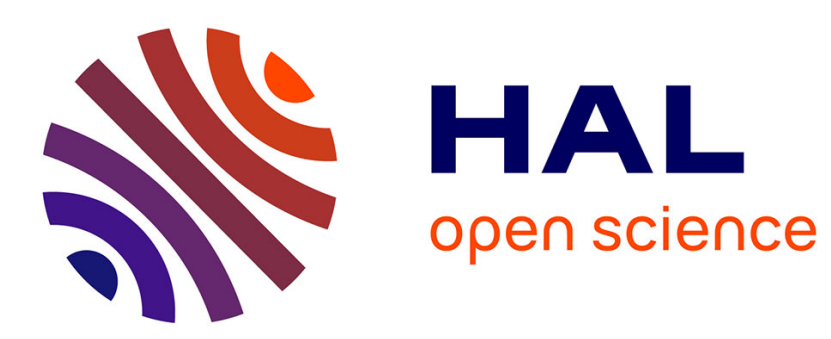

\title{
Antipodal radiation pattern of a patch antenna combined with superstrate using transformation electromagnetics
}

\author{
Mark Clemente Arenas, Anne Claire Lepage, Xavier Begaud
}

\section{To cite this version:}

Mark Clemente Arenas, Anne Claire Lepage, Xavier Begaud. Antipodal radiation pattern of a patch antenna combined with superstrate using transformation electromagnetics. Applied physics. A, Materials science \& processing, 2014, pp.1-5. 10.1007/s00339-014-8725-4 . hal-01068767

\section{HAL Id: hal-01068767 https://hal.science/hal-01068767}

Submitted on 26 Sep 2014

HAL is a multi-disciplinary open access archive for the deposit and dissemination of scientific research documents, whether they are published or not. The documents may come from teaching and research institutions in France or abroad, or from public or private research centers.
L'archive ouverte pluridisciplinaire HAL, est destinée au dépôt et à la diffusion de documents scientifiques de niveau recherche, publiés ou non, émanant des établissements d'enseignement et de recherche français ou étrangers, des laboratoires publics ou privés. 


\title{
Antipodal radiation pattern of a patch antenna combined with superstrate using transformation electromagnetics
}

\author{
Mark Clemente Arenas • Anne Claire Lepage \\ Xavier Begaud
}

Received: 30 May 2014/ Accepted: 11 August 2014

(C) Springer-Verlag Berlin Heidelberg 2014

\begin{abstract}
This paper aimed to show the design and performances of a flat superstrate placed above an L-band patch antenna. Obtained from the Transformation Electromagnetics technique, this superstrate enables to produce an antipodal radiation with a quasi-null radiation in the broadside direction. From the analytical transformations used for the calculation of the constitutive parameters, material permittivity and permeability profiles of the superstrate are deduced. Then, the field distribution and radiation patterns of the whole structure confirm the antipodal radiation behavior.
\end{abstract}

\section{Introduction}

Since 2006, the work of Pendry about Transformation Electromagnetics (TE) inspired several groups to design exotic devices for many fields as electromagnetism, optics, acoustics, etc. The flexibility in the control of wave propagation allows designing enigmatic devices such as invisibility cloak $[1,2]$ but also to modify the farfield of a patch antenna combined with a TE-based device as in [3-6].

In this article, the proposed device enables the fields to propagate toward the sides $\left(\theta= \pm 90^{\circ}\right.$ direction) instead of broadside $\left(\theta=0^{\circ}\right.$ direction) as a classical patch antenna does. Usually, when a planar antenna is placed or

M. Clemente Arenas - A. C. Lepage $\cdot$ X. Begaud $(\bowtie)$

Institut Mines Télécom, Télécom ParisTech - CNRS LTCI,

46 rue Barrault, 75634 Paris Cedex 13, France

e-mail: xavier.begaud@telecom-paristech.fr

M. Clemente Arenas

e-mail: mark.clemente@ telecom-paristech.fr

A. C. Lepage

e-mail: anne-claire.lepage@ telecom-paristech.fr conformed on a structure, a broadside radiation pattern is obtained. However, in many applications, like airborne systems, it will be interesting to have an exotic radiation pattern where two opposite main beams are generated close to the structure. This last peculiar behavior can be very interesting for applications where protuberate antennas are not allowed because of mechanical constraints. To achieve this kind of radiation, we propose to design a flat superstrate based on TE and to put it above an L-band patch antenna.

First, the principle of the design of the superstrate and the analytical transformations are shown. Then, the description of the $2 \mathrm{D}$ and 3D designs and the corresponding simulations results are presented for discussion and analysis. Finally, conclusions are drawn.

\section{Analytical transformation and 2D structure}

In this section, the analytical transformations are presented on a $2 \mathrm{D}$ structure to simplify the design process. Then, this $2 \mathrm{D}$ structure is rotated around $x$-axis to create the complete structure, which is described in the next section.

The design principle for the 2D superstrate is presented in Fig. 1. Two spaces are described. We notice that the virtual space is divided into two symmetrical parts.

Equation 1 describes the transformation, both $x$ and $y$ coordinates are transformed.

$x_{1,2}^{\prime}=\frac{w}{d} \sqrt{(a x)^{2}+\left(y \mp \frac{L}{2}\right)^{2}}, y_{1,2}^{\prime}=\frac{L}{\pi} \tan ^{-1}\left(\frac{y \mp \frac{L}{2}}{a x}\right)$

Then, the calculations for the constitutive parameters are performed using TEs $[1,2]$. It is also needed to simplify the permittivity and the permeability tensors in order to 


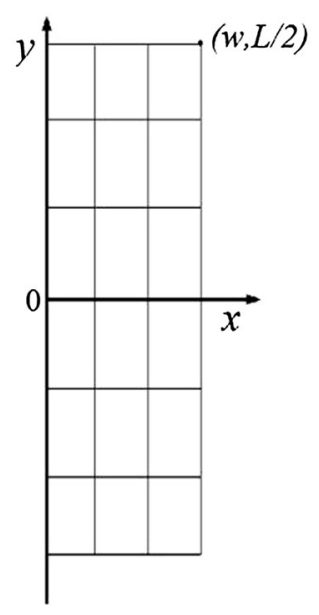

(a)

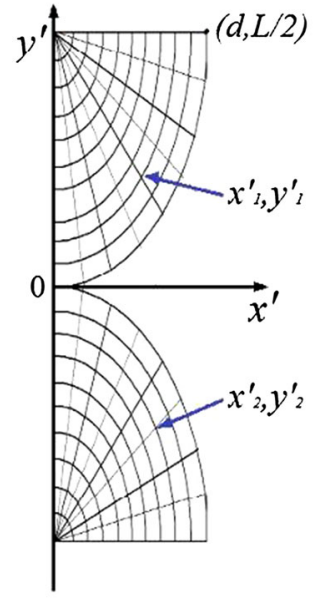

(b)
Fig. $1 L=200 \mathrm{~mm}, d=37.5 \mathrm{~mm}, \mathrm{w}=37.5 \mathrm{~mm}, a=2$ (compression factor). a Real space. b Virtual space

achieve a realistic material profile $[3,6]$. The reduced set of components of the permittivity and permeability tensors is shown in Eq. 2.

$\varepsilon_{z z}^{1,2}=4\left(\frac{\pi}{L} x_{1,2}^{\prime}\right)^{2}, \mu_{y y}^{1,2}=\left(\frac{L}{\pi \cdot x_{1,2}^{\prime}}\right)^{2}$

There are two symmetrical substructures for the proposed superstrate, each one has an identical equation, and only the sign is changed. This transformation aims to guide the fields toward the sides of the structure; this is the reason to use a shifted semi elliptical transformation.

As previously mentioned, the components of the tensors of constitutive parameters are reduced, and $\varepsilon_{z z}$ and $\mu_{y y}$ are the only nonzero values, and their values are shown in Fig. 2.

In order to evaluate the electromagnetic behavior of the device, the electric near field is analyzed at $1.2 \mathrm{GHz}$. Comsol Multiphysics is used to perform simulations where an anisotropic and inhomogeneous material is needed.

The antenna is modeled by a surface current, a PEC ground plane, and a dielectric. Then, the normalized electric field distribution $E z$ for the 2D structure, respectively, the antenna model without and with TE-based superstrate, is presented in Fig. 3a, b.

It is observed that the patch antenna, modeled with a surface current, has a directive radiation as expected. After, when the TE-based superstrate is placed over the antenna, the electric field is split into two and propagates toward the sides of the antenna.

\section{Complete structure and results}

In order to confirm the performances of the superstrate, the antenna radiation pattern obtained with or without it has

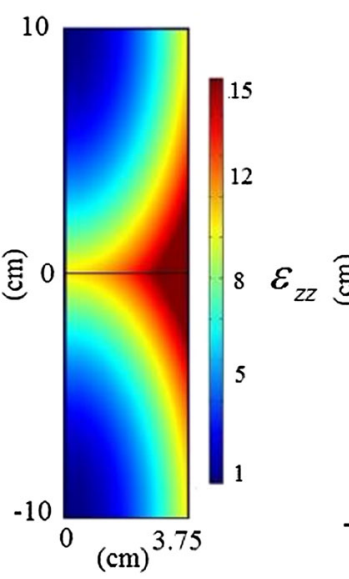

(a)

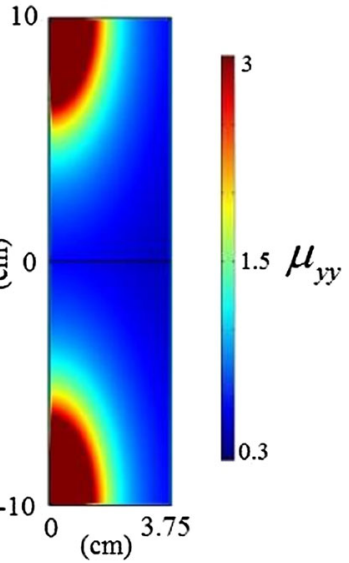

(b)
Fig. 2 Component $\varepsilon_{z z}$ from permittivity tensor. b component $\mu_{y y}$ from permeability tensor

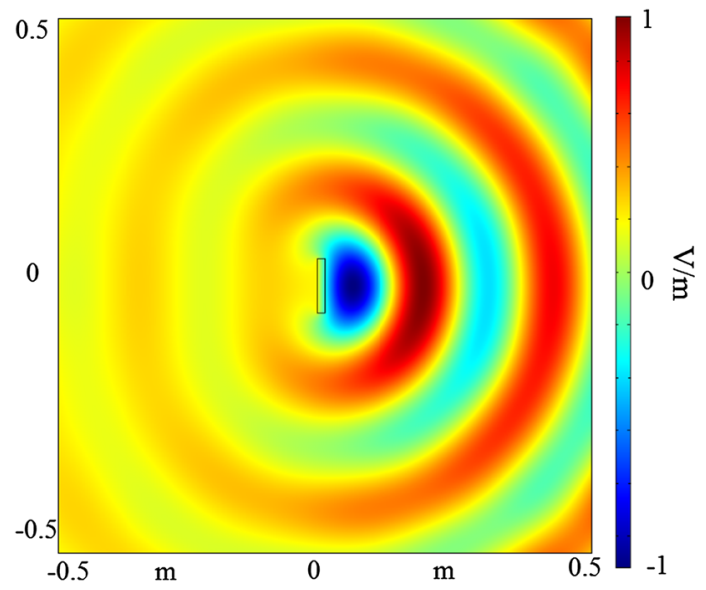

(a)

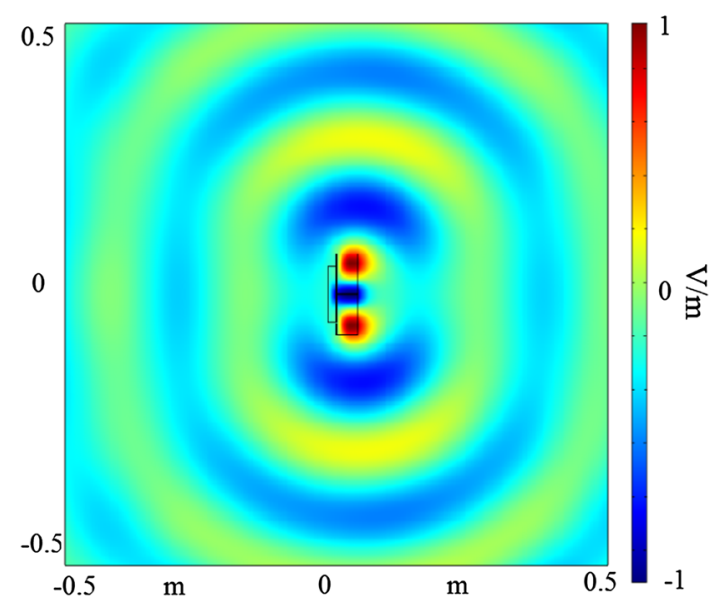

(b)

Fig. $32 \mathrm{D}$ Simulation of $E z$ field distribution at $1.2 \mathrm{GHz}$ for: $\mathbf{a}$ antenna model only and $\mathbf{b}$ antenna model with TE-based superstrate 
been calculated with CST Microwave Studio. A probe fed patch antenna has been designed in order to work in the L-band with the superstrate. The antenna substrate is a $100 \times 100 \mathrm{~mm}^{2}$ square with $15.5 \mathrm{~mm}$ of thickness, and the size of the patch is $65.5 \times 65.5 \mathrm{~mm}^{2}$. The substrate is Arlon $\operatorname{AD} 250\left(\varepsilon_{r}=2.5\right)$, and the ground plane has the same size as the substrate.

The 3D TE-based structure with the patch antenna is simulated using the discretized values of constitutive parameters $\varepsilon_{z z}$ and $\mu_{y y}$ shown in Fig. 4. It means that these profiles for both permittivity and permeability are divided into blocks of constant value (the average value of $\varepsilon_{z z}$ and $\mu_{y y}$ ), and then, these $2 \mathrm{D}$ blocks are converted into $3 \mathrm{D}$ concentric rings. Therefore, three multi-annular layers constitute the superstrate.

Different configurations are explored in order to obtain the patch antenna with the superstrate matched in the desired frequency band (1.16-1.2 GHz). In Fig. 5, the magnitude of the input reflection coefficient of the complete structure is presented for these cases.

First, we observe that the antenna without superstrate is matched around $1.3 \mathrm{GHz}$. Then, the impedance matching of the complete structure without any inter-layer is clearly affected in the operating band by two major causes. The first one is that there are high values of permittivity and low values of permeability in direct contact with the radiating surface. The second is the discretization of the continuous

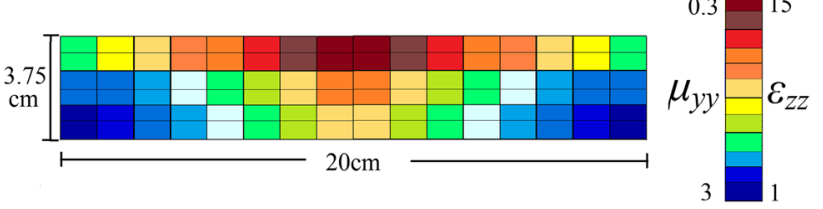

Fig. 4 Discretized profile for permittivity and permeability

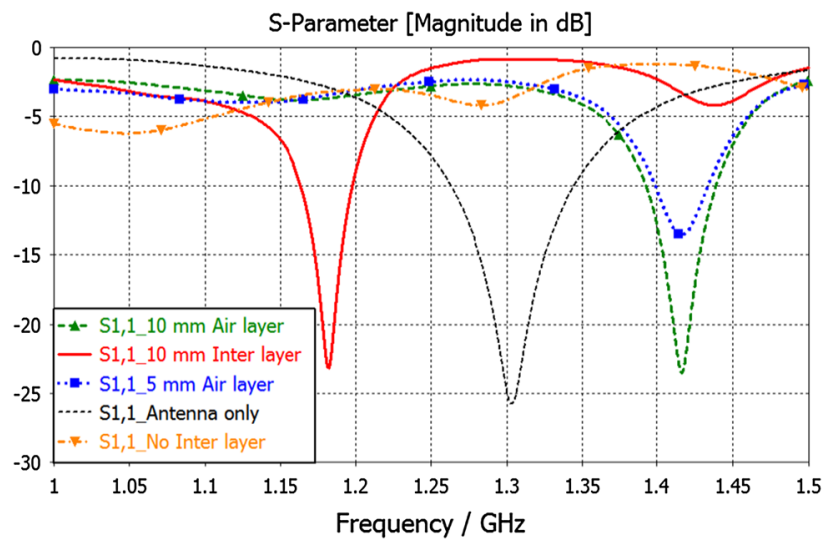

Fig. 5 Magnitude of input reflection coefficient of the complete structure with different configurations values of the constitutive parameters $(\varepsilon$ and $\mu$ ), which introduces reflections between each layer.

Adding an air layer between the antenna and the superstrate enables to recover one operating bandwidth but at higher frequencies than the targeted one. Finally, a transition layer of $10-\mathrm{mm}$ thickness and $\varepsilon_{r}=4$ is placed between the patch antenna and the superstrate to obtain the desired frequency band. This layer increases the thickness of the whole device from $53 \mathrm{~mm}$ to $63 \mathrm{~mm}$ for the final structure.

In Fig. 6, the $E z$ field distributions of the patch alone and of the complete structure are presented in their operating frequency band. It is observed how the electric field travels toward the side of the structure thanks to the superstrate, instead of traveling in axial direction.

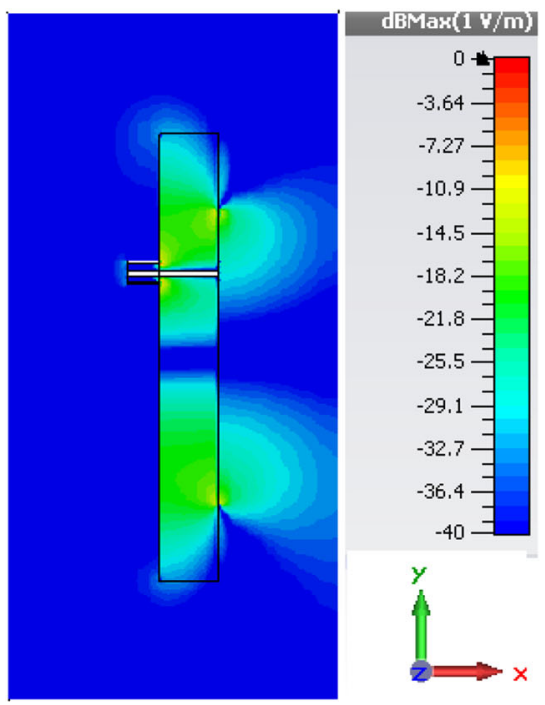

(a)

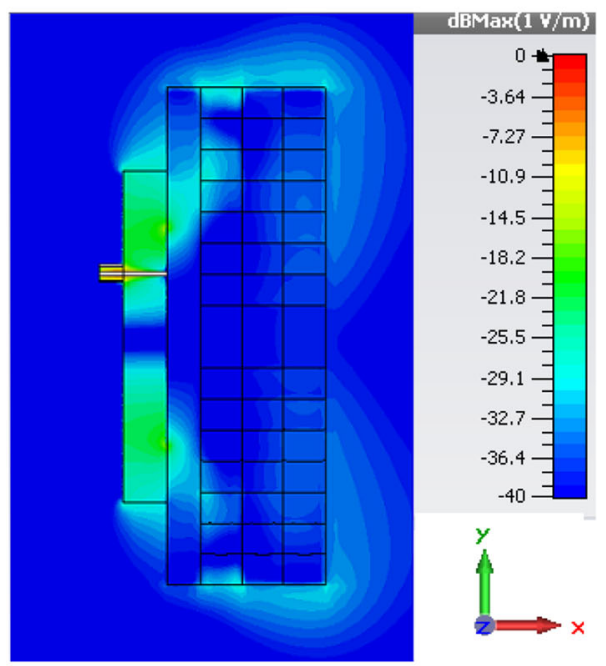

(b)

Fig. 6 a $E z$ field Distribution at $1.3 \mathrm{GHz}$ for the patch only and $\mathbf{b} E z$ field Distribution at $1.2 \mathrm{GHz}$ for the complete structure 


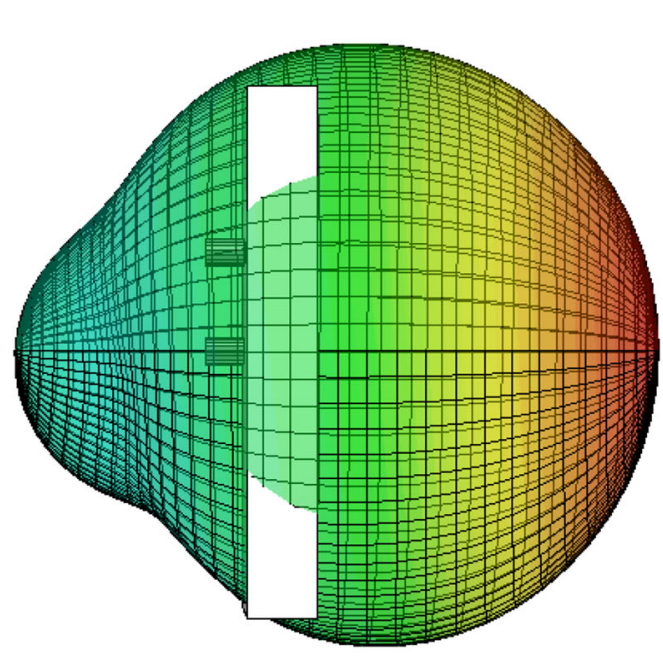

(a)
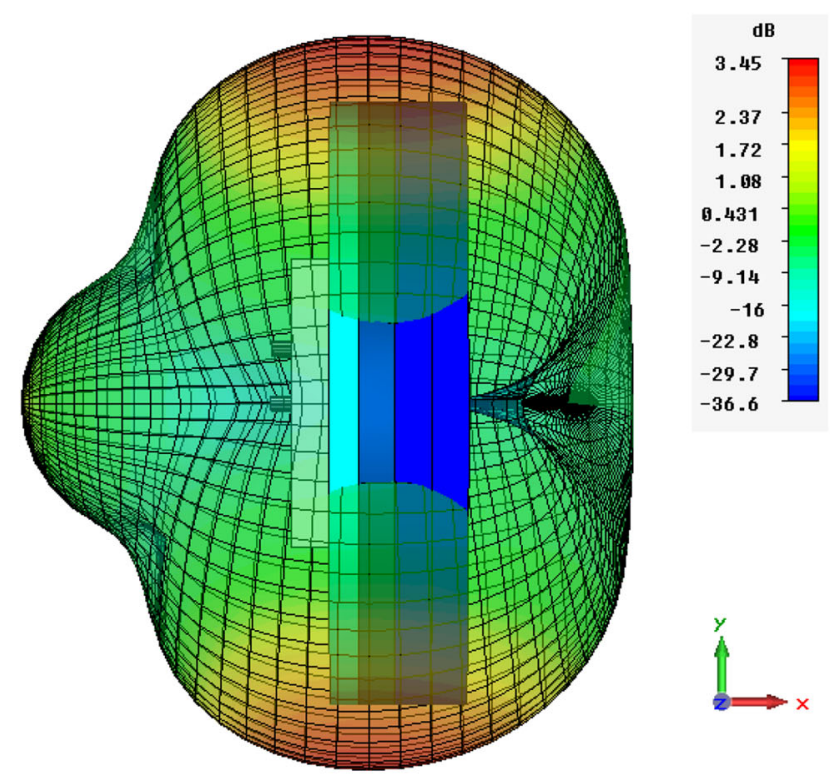

(b)

Fig. 7 Magnitude of the realized gain for: a patch only at $1.3 \mathrm{GHz}$ and $\mathbf{b}$ patch with TE-based superstrate at $1.2 \mathrm{GHz}$

In order to highlight the performances of the complete structure, the 3D radiation patterns are presented in Fig. 7 with and without superstrate. In Fig. 7a, the radiation pattern of the patch antenna only calculated at $1.3 \mathrm{GHz}$ shows that the radiation is maximum at $0^{\circ}$ (broadside) with a realized gain of 4.2 and $-8.5 \mathrm{~dB}$ at $\pm 90^{\circ}$.

Therefore, in Fig. $7 b$, the antenna and the TE device produce at $1.2 \mathrm{GHz}$ an antipodal radiation pattern with two main beams along the sides with maximum realized gain of $3.5 \mathrm{~dB}$ at $\pm 89^{\circ}$ and $-14.9 \mathrm{~dB}$ in the broadside direction.

The co-polar and cross-polar components of the realized gain in the two main planes of antenna $\left(\phi=0^{\circ}\right.$ and

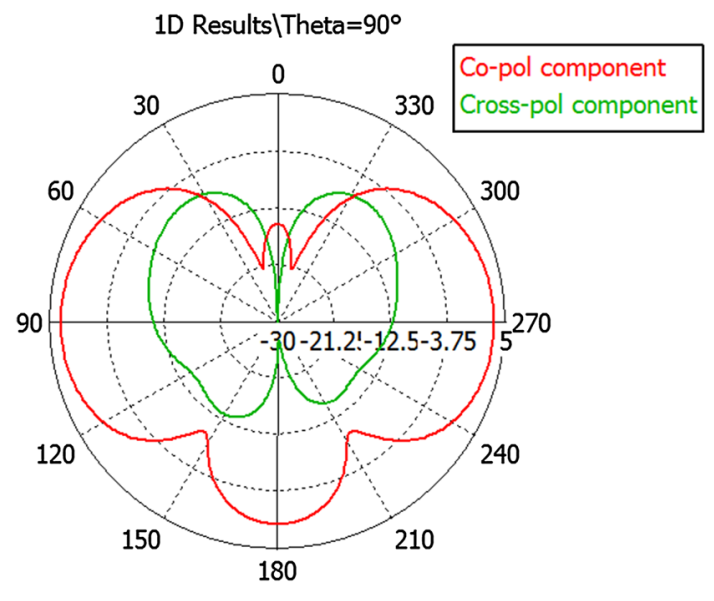

Phi / Degree vs. dB

(a)

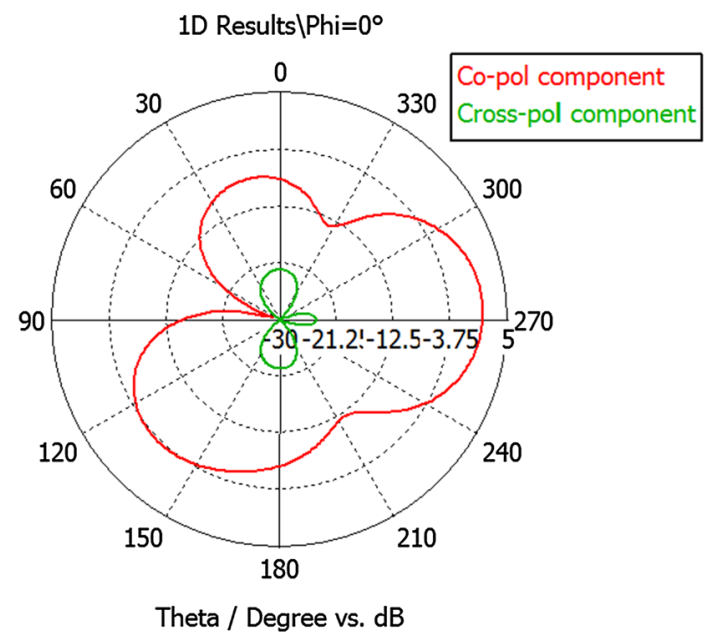

(b)

Fig. 8 Co-polar and cross-polar components of the realized gain in the two main planes of antenna at $1.2 \mathrm{GHz}$. a $\theta=90^{\circ}$. $\mathbf{b} \phi=0^{\circ}$

$\theta=90^{\circ}$ ) are presented in Fig. 8. In the plane $\theta=90^{\circ}$, the two main lobes are close to the antipodes, and a third lobe in the $\phi=180^{\circ}$ direction is also present with a lower level $(-2.2 \mathrm{~dB}$ compared with the main lobes). The level of cross-polar component is low.

In the other plane $\theta=0^{\circ}$, the radiation pattern is strongly backwards directed. It presents $1.3 \mathrm{~dB}$ of realized gain in the main direction $\left(\theta=274^{\circ}\right)$. Two other lobes are directed to $12^{\circ}$ and $133^{\circ}$. They are quite asymmetrical compared with the ones in the other plane. The level of cross-polar component is very low.

\section{Conclusion}

This paper demonstrates the performances of a superstrate based on TE technique. This flat device produces an 
interesting electromagnetic behavior with a L-band patch antenna, as there is an antipodal radiation with a realized gain equal to $3.5 \mathrm{~dB}$ at $\pm 89^{\circ}$, then dropping off to the minimum in the broadside direction, which is slightly similar to a dipole pattern. Using the designed TE device decreases the maximum realized gain of the patch antenna, which results of the creation of the two lobes.

In addition, as this superstrate is flat, it can be used for some applications, where shape and conformability are highly important. Thickness of the superstrate is equal to $37.5 \mathrm{~mm}$, which corresponds to 0.15 wavelength at $1.2 \mathrm{GHz}$.

Acknowledgments The research leading to these results has received funding by British and French Ministries of Defence (DSTL and DGA), through the European Defence Agency (EDA) contract MIMiCRA (Metamaterial Inspired Microwave Conformal Radar Antennas).

\section{References}

1. J.B. Pendry, D. Schurig, D.R. Smith, Controlling electromagnetic fields. Science 312, 1780-1782 (2006)

2. D. Schurig, J.J. Mock, B.J. Justice, S.A. Cummer, J.B. Pendry, A.F. Starr, D.R. Smith, Metamaterial electromagnetic cloak at microwave frequencies. Science 314, 977-980 (2006)

3. P.H. Tichit, S.N. Burokur, D. Germain, A. De Lustrac, Design and experimental demonstration of a high-directive emission with transformation optics. Phys. Rev. B 83(15), 155108 (2011)

4. D.H. Kwon, D.H. Werner, Transformation electromagnetics: an overview of the theory and applications. Antennas Propag. Mag. IEEE 52(1), 24-46 (2010)

5. P.H. Tichit, S.N. Burokur, A. De Lustrac, Ultra-directive antenna via transformation optics. J. Appl. Phys. 105(10), 1049121049126 (2009)

6. M. Clemente Arenas, A.C. Lepage, X. Begaud, P.H. Tichit, A. De Lustrac, All standard materials flat reflector made by transformation electromagnetics. Int J Microw Wirel Technol 6(2), 201-206 (2014). doi:10.1017/S1759078714000026 